Cuadernos de Filología Clásica. Estudios Latinos

ISSN: 1131-9062

https://dx.doi.org/10.5209/cfcl.64889

\title{
Medea recuerda su pasado literario: análisis intertextual de la Heroida 12 de Ovidio y las Argonáuticas de Apolonio de Rodas
}

\author{
Alba Blázquez Noya ${ }^{1}$
}

Recibido: 5/02/2017 / Aceptado: 31/01/2019

Resumen. Las fuentes de la Carta de Medea a Jasón de Ovidio han sido objeto de un exhaustivo estudio, sin embargo existe cierta escasez de trabajos comparativos modernos que establezcan de manera sistematizada su relación intertextual con sus posibles modelos. Por ello, este artículo tiene como objetivo demostrar la relevancia de las Argonáuticas de Apolonio de Rodas como intertexto de la Heroida 12. Para conseguirlo se señalarán y se analizarán los procesos intertextuales existentes entre ambas obras. En primer lugar, se estudiarán los primeros 128 versos de la epístola, una parte narrativa que sigue el hilo cronológico de los cantos 3 y 4 de las Argonáuticas. En segundo lugar, se analizarán los últimos 54 versos, que conforman un monólogo subjetivo plagado de referencias a lo narrado en dichos cantos de la epopeya. En definitiva, en este estudio se pondrán de manifiesto las funciones que cumplen en la carta los intertextos de la epopeya y se evidenciará cómo Medea construye su historia utilizando el recuerdo de su pasado literario.

Palabras Clave: Medea; Heroidas; Argonáuticas; intertextualidad.

\section{[en] Medea remembers her literary past: intertextual analysis of Ovid's Heroides 12 and Apollonius Rhodius' Argonautica}

\begin{abstract}
The sources of the Ovid's Letter from Medea to Jason have been the subject of a thorough study, however there is a shortage of modern comparative studies that systematize its intertextual relationship with its possible sources. Therefore, this article aims to demonstrate the relevance of Apollonius Rhodius' Argonautica as an intertext of Heroides 12, and for this purpose the intertextual processes between both works will be indicated and analyzed. On the one hand, the first 128 verses of the epistle will be analyzed proving that this is a narrative part that follows the chronological thread of the story recounted in chants 3 and 4 of Argonautica. On the other hand, we will study the last 54 verses, which make up a subjective monologue plagued with references to what is told in these chants of the epic. In short, this study will reveal the functions that the intertexts of the epic fulfill in the letter and will show how Medea builds his story by using the memory of his literary past.
\end{abstract}

Keywords: Medea; Heroides; Argonautica; intertextuality.

Sumario. 1. 1. La llegada de los Argonautas: Medea se enamora de Jasón(Ov.Epist.12.23-56; A.R.3.167450). 2. La lucha interna de Medea entre el amor y el deber filial (Ov.Epist.12.57-66; A.R.3.451-824). 3. El primer encuentro a solas de Medea y Jasón (Ov.Epist.12.67-92; A.R.3.828-1172). 4. El desarrollo de las pruebas y el robo del vellocino (Ov.Epist.12.93-108; A.R.3.1278-1407 y A.R.4.100-166). 5. Medea y Jasón huyen de la Cólquide (Ov.Epist.109-128; A.R.4.167-1781). 6. El final de la carta: recuerdos de las Argonáuticas (Ov.Epist.12.159-212). 7. Consideraciones finales.

1 Universidad de Salamanca, Universidad de Valladolid albablazqueznoya@gmail.com 
Cómo citar: Blázquez Noya, A., «Medea recuerda su pasado literario: análisis intertextual de la Heroida 12 de Ovidio y las Argonáuticas de Apolonio de Rodas», en Cuad. Filol. Clás. Estud. Lat. 39.1 (2019), 11-28.

El análisis literario de las Heroidas de Ovidio suscita cuestiones muy interesantes desde el punto de vista teórico. En los últimos años se ha desarrollado una potente corriente de estudio que se ha centrado en el análisis de la intertextualidad y la intersección de géneros literarios presente en esta colección (Rosati 1993, Casali 1995, Jolivet 2001, Barchiesi 2001a, Barchiesi 2001b, Kennedy 2002). Cada una de las cartas compone un complejo marco genérico en el que se encuadra la voz de las heroínas. Esto significa que las Heroidas no son simples monólogos en forma epistolar, sino que al cuerpo de la carta se incorporan elementos elegíacos, dramáticos y épicos, debido a la presencia por un lado, del género más cercano a ellas, la elegía, y por otro de la contribución a la obra de intertextos de la tragedia y la épica. El análisis individual de cada carta resulta en consecuencia muy largo y complejo. En el presente estudio tenemos el objetivo de demostrar la relación de una de las Heroidas, la Carta de Medea a Jasón, con la épica, concretamente con las Argonáuticas de Apolonio ${ }^{2}$.

En el momento en que Ovidio aborda el tema de Medea, en la literatura grecolatina se encontraban ya tratados diversos aspectos del mito: la historia de cómo Medea ayudó a Jasón a conseguir el vellocino de oro (la Pítica 4 de Píndaro; las fragmentarias Colchides y Scythiae de Sófocles; Argonáuticas de Apolonio de Rodas; Medea siue Argonautae de Accio; Argonáuticas de Varrón); los poderes rejuvenecedores y destructores de Medea (Trophoi de Esquilo y Peliades de Eurípides); el intento de Medea de matar a Teseo (el Aegeus de Eurípides); la historia de Medo, hijo de Medea (el Medus de Pacuvio); y por supuesto, la historia de la mujer abandonada que se venga de Jasón (la Medea de Eurípides y la Medea Exul de Ennio) ${ }^{3}$. De todas estas obras, qué modelo o modelos pudo usar Ovidio para componer la Heroida 12 entra necesariamente en gran medida en el terreno de la especulación si tenemos en cuenta que en muchos casos se trata de obras perdidas o fragmentarias. De todas formas, contamos con algunas bases firmes que nos guían en la búsqueda: por un lado, la crítica ha confirmado que Ovidio tuvo en cuenta las tragedias latinas arcaicas ${ }^{4}$; por otro, las semejanzas de la Medea de Eurípides y las Argonáuticas de Apolonio Rodio con la epístola resultan evidentes. Pero, si bien desde el siglo XIX se han señalado los pasajes similares más importantes de estas dos obras con el texto de la Heroida $12^{5}$, aún no se han estudiado sistemáticamente las relaciones entre ellas desde el punto de vista de la intertextualidad. La crítica, al centrar su atención en la influencia de la

2 Es conveniente señalar aquí que no pretendemos defender que las Argonáuticas sea el único o el más relevante intertexto de la carta. En el presente estudio planteamos el análisis intertextual con un único hipotexto de la Heroida dado que por cuestiones de espacio no sería posible en un mismo artículo estudiarlos todos. Nos remitimos a nuestro artículo (Blázquez Noya 2017), donde analizamos el proceso intertextual entre la Heroida 12 y la Medea de Eurípides con el fin de ver mediante la comparación con una obra dramática conservada completa cómo los elementos codificados de la tragedia se transfieren y se adaptan al género de la Heroida. Un análisis que tenga en cuenta todos los posibles hipotextos en sus diferentes niveles podrá ser objeto de ser publicado en un medio más adecuado para un trabajo de tal envergadura.

Boyle (2012, 1-27) recoge todas las obras de la literatura grecorromana en que se ha representado a Medea.

4 Knox $(1986,213)$, Hinds $(1993,35)$ y Barchiesi $(2001 b, 112)$ apuntan que en la Heroida 12 se encuentran coincidencias con el léxico presente en dichas obras.

5 Jacobson $(1974,110)$ señala que el trabajo de Birt (1877), Zoellner (1892), Anderson (1896) y Tolkiehn (1902) estableció sin ninguna duda que Ovidio utilizó a Eurípides y a Apolonio como fuentes de la Heroida 12. 
Medea de Ovidio y de los modelos dramáticos de la Heroida 12 (Knox 1986, Hinds $1993)^{6}$, ha desatendido la presencia de las Argonáuticas de Apolonio en la epístola.

El hecho de que la Heroida esté compuesta en forma epistolar no impide que la voz monológica de la escritora adquiera distintos tonos: a veces es un monólogo elegíaco, otras se impregna de tintes dramáticos, y otras se convierte en monólogo narrativo. Las heroínas de la colección narran mucho más de lo esperado en el marco de la elegía epistolar, y lo hacen porque necesitan la forma narrativa para recordar su pasado e incorporarlo al contexto del relato de su historia en la carta. Este pasado que las heroínas narran suele corresponder a momentos del mito que ya han sido tratados en obras anteriores, y con la narración en primera persona Ovidio les permite entrar en negociación con ellas para reescribir su propia versión de la historia ${ }^{7}$. Por eso es tan importante la localización de los intertextos en el estudio de las Heroidas; y en el caso de la composición de la carta de Medea, las Argonáuticas de Apolonio adquieren un relevante papel, como pretendemos demostrar.

Una importante parte de la Heroida 12 (23-128) resume ${ }^{8}$, bajo la forma de monólogo epistolar, los acontecimientos que se recogen en la narración épica de los cantos 3 y 4 de las Argonáuticas ${ }^{9}$ y que giran en torno a Medea. El hilo conductor del discurso de nuestra heroína en la carta es, como pondremos de manifiesto, la evocación narrativa de estos avatares. Sin embargo no debemos olvidar que, aunque en términos de contenido la carta se acerca más a las Argonáuticas que a las tragedias que narran los acontecimientos ocurridos posteriormente en Corinto, el momento del mito en que se inserta el propio acto de escritura de la carta es posterior a lo acontecido en las Argonáuticas. En trabajos anteriores ya hemos defendido cuál sería el momento en que se inserta la Heroida 12: Medea escribe su epístola poco después de la boda de Jasón con su nueva mujer Creúsa y justo antes de comenzar a planear su venganza contra él (Blázquez Noya 2017, 774) ${ }^{10}$. Así, aunque encontremos elementos dramáticos que apuntan irónicamente a su futuro trágico, este monólogo elegíaco que es la Heroida 12 se orienta hacia el tiempo pasado y desarrolla los recuerdos que la heroína rememora sobre su vida en la Cólquide ${ }^{11}$. Una vez hemos apuntado estas consideraciones previas, nos disponemos a analizar la carta en relación a su intertexto apolonio.

El principio de la carta (1-22) constituye un monólogo subjetivo de lamento con el que nuestra escritora introduce y contextualiza el grueso de su discurso. En este monólogo inicial Medea se lamenta de lo que ocurrió y ella desearía que no hubiera ocurrido: por un lado, desea que no hubieran llegado a su tierra los Argonautas,

6 Así como en los análisis comparativos con la Carta de Hipsipila a Jasón (Verducci 1985, Jolivet 2001, Lindheim 2003, Fulkerson 2005).

7 Las heroínas se han prototipizado con la tradición, algo que, escribiendo su historia desde cero, pueden subvertir (Kennedy 2002).

8 Es importante recalcar que a la evocación del pasado se le dedica la mitad de la carta (106 versos de un total de 212).

$9 \quad$ Este aspecto ha sido señalado por Davis $(2012,38)$ pero no analizado sistemáticamente.

10 De esta manera, el presente de la Heroida se sitúa en un momento muy concreto entre las Argonáuticas y las tragedias de la venganza de Medea. Recordemos que la epopeya narra el principio de la historia de amor de Medea y Jasón, y en cambio las tragedias (la Medea de Eurípides, la Medea Exul de Ennio y seguramente también la Medea de Ovidio) sitúan la acción años después, cuando, tras ser exiliada en Corinto y tras haberse casado Jasón con su nueva esposa Creúsa, Medea planea su venganza y ejecuta a sus hijos.

11 Verducci $(1985,71)$ afirma que no hay ninguna otra carta de la colección de las Heroidas cuya estructura esté tan dominada por la narración de eventos del pasado recordados desde la perspectiva del presente. 
evocando el final del canto 2 de la epopeya en el que los griegos llegan a la Cólquide (Ov.Epist.12.7-10; A.R.1277-1278); y por otro lado, anhela no haberse enamorado de Jasón, aludiendo a la escena del enamoramiento de la épica (Ov.Epist.12.11-12; A.R.281-301). También se queja nuestra heroína de aquello que no ocurrió pero desearía que hubiera ocurrido: desea no haber ayudado a Jasón, con la consiguiente muerte de este en las pruebas (Ov.Epist.12.13-20), y así evoca lo narrado en el canto 3 de la epopeya sobre las pruebas y la ayuda de Medea (A.R.3.1272-1407). Vemos de esta manera que los primeros versos de la epístola, sin llegar a ser narrativos, tienen una función introductoria puesto que hace referencia a los lances más relevantes de la historia que relata después: la llegada de los Argonautas a la Cólquide, el enamoramiento de Medea y la ayuda que la heroína le brindó a Jasón en las pruebas.

Pero no sólo encontramos evocación de avatares narrados en las Argonáuticas, sino que también se pueden apreciar concomitancias entre la voz de la Medea ovidiana en estos versos de la carta y la voz de la joven Medea épica, que en varias ocasiones se expresan en unos términos muy similares. La Medea de la carta afirma que ella recuerda lo ocurrido en la Cólquide ${ }^{12}$ y se arrepiente de haber traicionado a su familia, incluso desea la muerte antes de haber tenido ocasión de ayudar a Jasón (Ov.Epist.12.1-6) ${ }^{13}$. La Medea apolonia comparte con la ovidiana este terrible deseo de morir desde el mismo momento en que siente el impulso de ayudar a Jasón (A.R.3.766-801), incluso quiere suicidarse (A.R.3.802ff.). Además, la heroína apolonia maldice a su amado Jasón deseándole la muerte en una imprecación que se puede comparar al deseo de la ovidiana de que nunca hubieran llegado a la Cólqui-

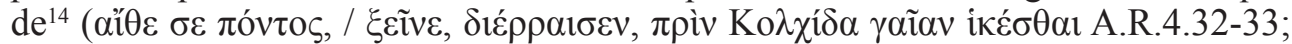
Cur umquam Colchi Magnetida uidimus Argon / Turbaque Phasiacam Graia bibistis aquam (15 $^{15}$ Ov.Epist.12.9-10). Como vemos, en esta parte subjetiva del discurso, la Medea de la carta se deja influir por la actitud y la voz de su predecesora literaria.

Tras este monólogo subjetivo de lamento imprecatorio, nuestra heroína dice: Est aliqua ingratum meritum exprobrare uoluptas; / Hac fruar, haec de te gaudia sola feram (Ov.Epist.12.21-22). Con esta frase la Medea ovidiana da pie a una parte narrativa de la Heroida (23-128) que sigue el hilo argumental de las Argonáuticas, relatando, como veremos, los siguientes pasajes de los libros 3 y 4: 1) la llegada de los Argonautas, la comparecencia de Jasón ante Eetes para pedirle el vellocino de oro y el enamoramiento de Medea (A.R.3.167-450; Ov.Epist.12.23-56); 2) la retirada de Jasón y la lucha interna de Medea entre el amor y el deber filial (A.R.3.451-824; Ov.Epist.12.57-66); 3) el encuentro secreto entre Medea y Jasón (A.R.3.828-1172; Ov.Epist.12.67-92); 4) la superación de las pruebas y el robo del vellocino (A.R.3.1272-1407 y A.R.4.100-166; Ov.Epist.12.93-108); y por último, 5) la huida de la Cólquide (A.R.4.167-1781; Ov.Epist.109-128) incluyendo el asesinato de su hermano (A.R.4.338-521) y la navegación resumida hasta llegar a Te-

12 El recuerdo del pasado es un elemento común tanto en las Argonáuticas como en las Heroidas (Davis 2012, 38). De acuerdo con Bessone (1997, 63, citado por Davis 2012, 38), el recuerdo en la epístola evoca la importancia de la memoria en Apolonio, donde Medea le pide a Jasón que la recuerde (A.R.3.1109-11). Y más adelante le

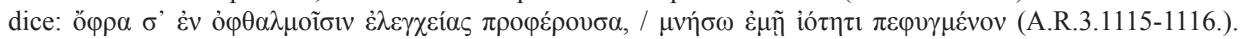
Seguimos la edición del texto griego de las Argonáuticas de Mooney (1912).

13 También más adelante ansía que el mar se los hubiese tragado, a ella y a Jasón, mientras huían (Ov.Epist.12.119-126).

14 Una imprecación que también se puede comparar con las palabras que pronuncia la nodriza de Eurípides al comienzo de la tragedia (E.Med.1-2).

15 Seguimos la edición del texto latino de las Heroidas de Moya del Baño (1986). 
salia (A.R.4.522-1781). 6) A continuación, nuestra escritora cuenta los hechos que ocurren después de las Argonáuticas sin dejar de evocar acontecimientos del pasado apolonio (Ov.Epist.12.159-212) ${ }^{16}$. Como veremos, aunque el discurso de la carta sigue a Apolonio en la trama narrativa, eso no significa que Ovidio imite fielmente el modelo, sino que aprovecha las referencias a este hilo argumental para dialogar con él y crear interesantes juegos intertextuales, sirviéndose tanto del cambio en la perspectiva del narrador que se produce en la Heroida con respecto al hipotexto narrador extradiegético frente a narrador epistolar en primera persona- como de la divergencia en el momento del mito en el que se inserta la carta con respecto a lo narrado en la epopeya -el momento presente en el que Medea acaba de ser abandonada frente al pasado en la Cólquide en el que comienza su relación con Jasón.

\section{La llegada de los Argonautas: Medea se enamora de Jasón (Ov.Epist.12.23-56; A.R.3.167-450)}

La narradora de la carta, tras aludir a la llegada de los Argonautas a tierra colca (Ov. Epist.12.23-28), comienza su relato resumiendo la escena del libro 3 de las Argonáuticas en la que Eetes encomienda a Jasón las peligrosas labores necesarias para entregarle el vellocino, que es la escena en la que Medea ve por primera vez a Jasón y se enamora de él (Ov.Epist.12.29-56; A.R.3.275-450). En ambas obras se recoge la escena del enamoramiento expresada con los mismos motivos: el enamoramiento a primera vista (Ov.Epist.12.33, A.R.3.284-290), la llama que arde en el pecho de la enamorada (Ov.Epist.12.33-34; A.R.3.286-7), la belleza de Jasón (Ov.Epist.12.35; A.R.3.443-4) y las miradas de ella (Ov.Epist.12.36; A.R.3.444-5) ${ }^{17}$.

Pese a los elementos comunes en ambas obras en la descripción de la escena del enamoramiento, la epístola presenta una divergencia significativa: mientras que en las Argonáuticas el enamoramiento de Medea es orquestado por las diosas Hera y Atenea desde el propio principio del libro 3 para proteger a Jasón y es perpetrado por una flecha de Eros durante la escena que estamos comentando, en la epístola se omite la acción de los dioses (Ov.Epist.12.33-36; A.R.3.275ff.), quizás debido a que la intervención divina es un elemento convencional propio de la épica. Así, creemos que la omisión de la acción divina de esta escena en la Heroida responde a dos motivos: por un lado interviene una cuestión genérica, es decir, Ovidio consigue romper con el modelo épico al omitir una de sus convenciones más características, remarcando a su vez el estilo menos elevado de la carta elegíaca en la que se está reescribiendo la historia; y por otro lado hay una cuestión de perspectiva y de intenciones de la narradora, pues, dado que Jasón quedaría liberado de la culpa por el enamoramiento si este resulta ser obra y deseo de los dioses, al omitir la acción divina Ovidio consigue

16 Como se puede apreciar, en este resumen esquemático de las partes relacionadas intertextualmente no hemos incluido los versos 129-158 de la Heroida, en los que la heroína narra cómo vivió la boda de Jasón y Creúsa (Ov. Epist.12.133-158). Dado que en estos versos no hemos encontrado elementos intertextuales en los que la heroína evoque eventos de las Argonáuticas, consideramos que analizar este pasaje sobrepasa los límites del objetivo del presente trabajo, que es determinar en qué medida la Heroida 12 sigue el hilo narrativo de las Argonáticas.

17 Estos versos de la carta, contados desde la perspectiva de la propia enamorada en un monólogo subjetivo, tienen mucho en común con la elegía romana, y también con la elegía helenística en la que Apolonio había basado los pasajes amorosos de su epopeya (Giangrande 2002). 
que el discurso refleje la visión de Medea según la cual Jasón la manipuló utilizando su amor ${ }^{18}$.

Así, en la Heroida Ovidio adelanta e intensifica el motivo de la manipulación, que no está presente aún en la epopeya ${ }^{19}$ : no hay nada que indique que Jasón se fije en Medea durante su visita en el palacio, aunque de hecho Medea lo mira directamente cuando Amor le clava la flecha (A.R.3.287-8) y furtivamente cuando se marcha. Sin embargo, en la carta, la escritora describe cómo Jasón busca su mirada (Ov. Epist.12.36), lo cual le hace pensar que se dio cuenta de su amor y lo utilizó en su provecho: Perfide, sensisti. Quis enim bene celat amorem? / Eminet indicio prodita flamma suo (Ov.Epist.12.37-38). En la epístola así se insiste en el retrato de Jasón como seductor y embaucador frente al de la muchacha ingenua y crédula, y esta contraposición acentúa el carácter inocente de Medea y la culpabilidad de Jasón. Esta caracterización contrapuesta entre ambos personajes es compartida con las Argonáuticas, aunque vemos una diferencia: el autorretrato creado por la Medea de la carta no es el de la mujer que está escribiendo, sino el de la muchacha que fue años atrás; así, Medea presenta su yo del pasado como una muchacha ingenua y entra en negociación con este autorretrato, pues lo mira con arrepentimiento e incluso desprecio.

Después de representar la escena del enamoramiento, la epístola recoge, resumiéndolo y reproduciéndolo en estilo directo y en forma impersonal, el discurso de Eetes de las Argonáuticas en el que encomienda las misiones a Jasón (Ov.Epist.12.39-50; A.R.3.401-421), y lo cierra con una fórmula épica de la misma manera que se cierra

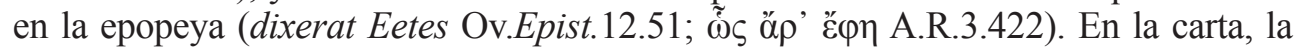
escena de Jasón en palacio finaliza relatando cómo Medea observa la retirada de éste, de igual manera que en la epopeya (Ov.Epist.12.55-56; A.R.3.445-448). Esta narración de la carta resume cómo vivió Medea lo relatado en esta parte del canto 3, y como es natural con el cambio de género, prescinde de aquellos elementos que no le interesan ${ }^{20}$.

\section{La lucha interna de Medea entre el amor y el deber filial (Ov.Epist.12.57-66; A.R.3.451-824)}

En la epopeya, tras la marcha de los Argonautas, todos se retiran y Medea se vuelve a su cuarto. La narración se centra entonces en relatar los hechos acaecidos en esa larga noche hasta que llega la mañana (A.R.3.451-824), y se abren dos narraciones paralelas: por un lado, las deliberaciones de los Argonautas tras la respuesta del rey,

18 La omisión en la Heroida de la acción divina en el enamoramiento de Medea es una divergencia importante especialmente si consideramos que en el proceso intertextual de este motivo está involucrado también el hipotexto más antiguo de ambas obras: la Medea de Eurípides. Como decíamos en el cuerpo de texto, Apolonio en las Argonáuticas explota este elemento como parte del código épico, pero no es una innovación en el mito de Medea, pues la influencia de los dioses en el amor de Medea la encontramos ya en Eurípides. No obstante, en la tragedia Jasón utiliza esta acción divina contra Medea como contraargumento a los reproches de esta: en la tragedia, cuando nuestra heroína le recuerda todo lo que hizo por él en el pasado, Jasón le responde que ella no actuó en contra de su familia a favor de él, sino porque Afrodita hizo que se enamorara (E.Med.526-531). Así, si tenemos en cuenta este intertexto de la tragedia, podremos apreciar que Ovidio, al omitir este motivo, consigue también no apoyar el argumento en contra de nuestra heroína procedente de su pasado literario.

19 En la epopeya Jasón también se da cuenta de que está enamorada y lo utiliza en su provecho, pero no durante la reunión con Eetes sino más adelante en su encuentro en el bosque (A.R.3.973-974).

20 Como ejemplo de esto, vemos en la carta una elipsis clara en el hecho de que se nos presenta a los Argonautas directamente en el banquete, omitiendo la descripción de su llegada a palacio y sus intenciones: reclamar el vellocino. 
y por otro, la lucha interna de Medea entre su amor y su deber filial. El conflicto interno de Medea se desarrolla en tres pasajes del libro 3 intercalados con los hechos de los griegos: según entra en el cuarto se recrea en el enamoramiento y en el temor por la vida de Jasón (A.R.3.451-471); tras despertarse sobresaltada por un sueño premonitorio, su hermana la visita para pedirle que ayude a los Argonautas, a lo que ella accede (A.R.3.616-743); a continuación, sin poder conciliar el sueño, empieza a dudar de su decisión y tiene la tentación de suicidarse, pero finalmente se convence de ayudar a Jasón (A.R.3.744-824). La narración pasa a describir la llegada de la mañana y cómo nuestra heroína se prepara para encontrarse con el héroe. Este conflicto interno, que en la epopeya se desarrolla extensamente y tiene muchas aristas, en la Heroida queda reducido a diez versos (Ov.Epist.12.57-66). Esos diez versos tienen referencias claras a elementos procedentes de estos pasajes de la epopeya, como veremos en seguida, pero están adaptadas a una nueva necesidad narrativa y epistolar propia de la Heroida.

Lo primero que conviene apuntar es que lo relatado en estos versos de la carta no se corresponde exactamente al desarrollo que se puede apreciar en la epopeya: mientras que en las Argonáuticas podemos ver las fases por las que pasan los sentimientos de la heroína a lo largo de la noche, espaciadas en esos tres pasajes que hemos señalado, en la carta (Ov.Epist.12.57-61) encontramos la descripción del estado anímico de Medea marcado por el llanto, mientras que el conflicto interno queda reducido a unas breves palabras: Hinc amor, hinc timor est; ipsum timor auget amorem $(\mathrm{Ov}$. Epist.12.61). De estas palabras se deduce la lucha interna de Medea, que tiene delante las dos opciones: el amor representa ayudarlo, el temor representa no ayudarlo, pues es el temor que siente por un Jasón que se enfrenta a las pruebas sin su ayuda. Pero la heroína no se extiende en describir su noche, y pasa directamente a contar que a la mañana siguiente aparece su hermana para pedirle ayuda. Esto significa que en la Heroida encontramos una variación cronológica, pues se sitúa la visita de la hermana por la mañana mientras que en la epopeya esta la visita en medio de la noche (Ov.Epist.12.62-66; A.R.3.616-744).

Con esta pequeña pero significativa variación cronológica, el relato de la heroína insinúa que no se decidió a ayudarlo en aquella noche, sino que fue su hermana quien la convenció de hacerlo (Ov.Epist.12.62-66). Esto diverge notablemente de la versión apolonia; en ella, Medea se había despertado sobresaltada por un sueño premonitorio sobre su destino con Jasón, tras lo cual sale a buscar a su hermana deseando que esta le pida ayuda y así poder liberarse de la culpabilidad que le suponía el deseo de salvar a su amado. Sin embargo, después de mucho dudar, no se atreve a llamar a la puerta, con la suerte de que es la propia hermana quien viene a visitarla (A.R.3.635ff.). Seguramente Ovidio diverge de esta versión porque recoger los afectos familiares de una hermana es menos conveniente para el discurso de la heroína enamorada de la carta, que justifica su propia inocencia haciendo notar que accedió a ayudar al héroe no porque lo deseara, sino porque su hermana se lo pidió. A este respecto, es conveniente considerar si la variación viene de la mano de Ovidio o es una manipulación de los hechos por parte de Medea. Creemos que el hecho de incluir una variación cronológica tan evidente le sirve al autor para tomar una distancia con respecto al modelo y que el lector de la Heroida pueda creerse la versión de la nueva Medea según la cual la razón principal para ayudar a Jasón no fueron sus propios intereses amorosos, sino concederle el deseo a su hermana (Ov.Epist.12.66). 
Pese a esta clara divergencia, las referencias que hace el relato de la carta al texto apolonio son constantes y en muchos sentidos lo resumen. Así, la contextualización general de la noche de Medea (Vt positum tetigi thalamo male saucia lectum, / Acta est per lacrimas nox mihi, quanta fuit 57-58) podemos encontrarla en el texto Apolonio: los llantos (Ov.Epist.12.58; A.R.3.460-463, 656-665, 761); estar tumbada en el lecho (Ov.Epist.12.57; A.R.3.654-655); el dolor del amor (Ov.Epist.12.57; A.R.3.761-765). También encontramos en ambas obras la misma manera de recor-

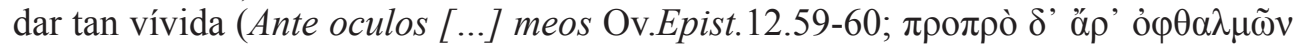
A.R.3.454). Y por supuesto, las referencias al amor y al temor alrededor de las cuales en la carta se configura la idea del conflicto interno ( $\pi \mathrm{o} \lambda \lambda \dot{\alpha} \delta \dot{\varepsilon} \theta v \mu \tilde{\omega} / \omega \tilde{\omega}_{\rho} \mu \alpha \mathrm{v} v$ ',

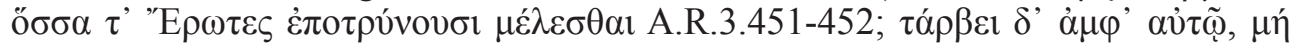

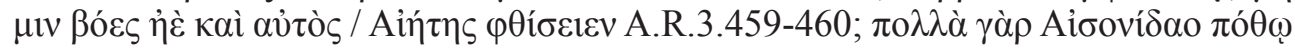

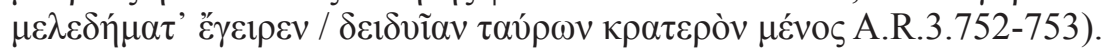

\section{El primer encuentro a solas de Medea y Jasón (Ov.Epist.12.67-92; A.R.3.828-1172)}

Tras este pasaje la Heroida relata el encuentro de Medea a solas con Jasón (Ov. Epist.12.67-92; A.R.3.975ff.). Mientras que en la epopeya encontramos un relato de cómo llegan ambos personajes al lugar de encuentro (A.R.3.828-972), en la Heroida este preámbulo queda reducido a las palabras uenimus illuc (Ov.Epist.12.71) plasmadas concisamente tras una descripción del bosque en el que se citan. En ambas obras es Jasón quien comienza a hablar, y el narrador/escritora incluye sus palabras en un discurso directo insertado en la narración. Este discurso se introduce en ambas obras refiriéndose a cómo Jasón manipula a Medea utilizando su enamoramiento (Orsus

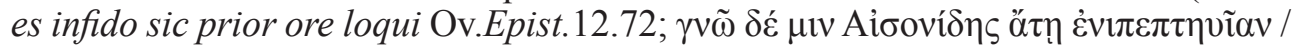

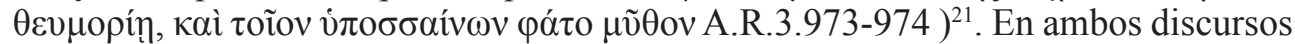
tenemos un Jasón suplicante que le promete a nuestra heroína la gloria a cambio de que le salve la vida. Pero encontramos divergencias significativas.

En las Argonáuticas tenemos una escena dialógica: primero habla Jasón suplicante ofreciéndole la gloria a cambio de su ayuda (A.R.3.990-992); le responde Medea explicándole los rituales mágicos que debe llevar a cabo (A.R.3.1026-1062), y, después de una pausa, retoma su discurso para pedirle que la recuerde tras su partida (A.R.3.1069-1071); a lo que Jasón contesta que si escapa a la muerte jamás se olvidará de ella (A.R.3.1079-180) e insinúa que puede que consiga llegar a un trato con su padre para que ella pueda irse con él (A.R.3.1100-1101); Medea rechaza esta proposición indirecta de Jasón y reitera que sólo quiere que la recuerde (A.R.3.11091111); ante lo cual él insiste en su propuesta ofreciéndole ya explícitamente un lecho legítimo y un amor eterno (A.R.3.1128-1130); después de esto se despide de ella. En definitiva, en la versión apolonia del primer encuentro, Medea le ofrece la ayuda sin pedirle nada a cambio, sólo que la recuerde, y no acepta, todavía, la propuesta

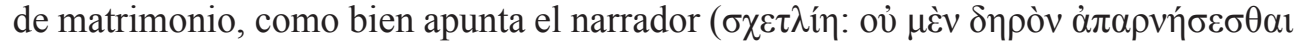

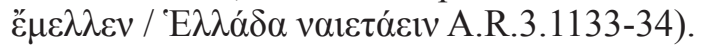

21 El retrato de Jasón como manipulador que se aprovecha del amor de la joven es común en ambas obras: el narrador de la epopeya insiste en que las palabras de Jasón están llenas de halagos (A.R.3.974,1008), y la narradora de la carta, que es la Medea del futuro con respecto a los hechos épicos, mira en retrospectiva esos primeros momentos con el héroe y se da cuenta de la actitud manipuladora de este para conseguir su ayuda (infido ore Ov.Epist.12.72; Sic cito sum uerbis capta puella tuis Ov.Epist.12.92). 
En la Heroida, la escena del primer encuentro a solas es aparentemente muy similar a la apolonia, pero está narrada de manera notablemente diferente. Lo primero y más esencial es que en la carta no tenemos un diálogo, sino un discurso aislado de Jasón, pues Medea no incluye en el relato su propia respuesta ${ }^{22}$. En ese sentido, conviene apuntar que lo que en la epopeya se desarrolla en tres intervenciones de Jasón, en la Heroida se condensa en una sola: las súplicas de la primera intervención se encuentran en los versos 77-81 y la proposición de las otras dos intervenciones en los versos 82-88. De esta manera, los sucesos según los presenta la carta, son notablemente diferentes que en la epopeya: se encuentran, Jasón pronuncia su discurso, ella acepta la propuesta de matrimonio (dextrae dextera iuncta meae Ov.Epist.12.90) y con esa alianza accede a ayudarlo.

Determinar en qué momento Medea acepta la propuesta de matrimonio es esencial para comprender la actitud de la muchacha en ambas obras, pues supone un punto de divergencia importante. El discurso de Jasón en la Heroida contiene el juramento ante los dioses de que si lo ayuda haría de ella su esposa, mientras que en las Argonáuticas en este primer encuentro sólo tenemos una propuesta, que Medea no acepta. En la epopeya, el juramento y la aceptación por parte de Medea de este compromiso no se produce en la escena del templo, sino muchos versos después en el libro 4 (Conscia sit Iuno sacris praefecta maritis, / Et dea marmorea cuius in

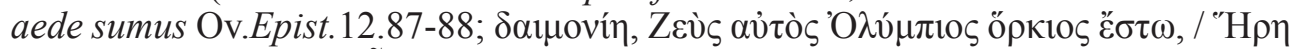

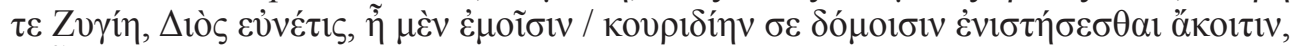

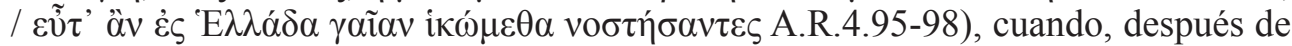
haber ayudado a Jasón, la heroína advierte el peligro que corre por la traición a su patria y se apresura a suplicar la protección y la promesa de matrimonio del Esónida (A.R.4.83-91), que ya le había hecho en el primer encuentro. Otro elemento que apunta a esta divergencia cronológica es que, en la Heroida, la escena del primer encuentro se cierra con la pareja dándose la mano como símbolo de consentimiento mutuo (Ov.Epist.12.89-92), un gesto que en la versión apolonia no ocurre en el libro 3, sino en el 4 (A.R.4.99-100) ${ }^{23}$, después de que Jasón pronuncie mencionado juramento a petición de Medea (A.R.4.95-98). Así, el compromiso de matrimonio es la razón por la que la Medea de la carta decide ayudarlo aliándose con él, mientras que la epopeya no lo es, puesto que lo ayuda sin condiciones y acepta la propuesta después de haberlo hecho.

Encontramos así en la Heroida una desviación con respecto al intertexto apolonio que consideramos que responde a dos razones. Por un lado, Ovidio, apoyado en la necesidad de mayor economía del género epistolar, efectúa una condensación temporal y representa en una sola escena ambos momentos del intertexto ${ }^{24}$, y en un solo monólogo lo que en el modelo es un diálogo extenso. Haciéndolo modifica sustancialmente los acontecimientos con respecto a la historia que narra Apolonio. Así, por otro lado Ovidio le ofrece a Medea en su Heroida un trasfondo que le sirve para justificar la traición a su familia con el voto sagrado del matrimonio ${ }^{25}$. En consecuencia, en la carta, lo que convence a nuestra heroína para actuar en contra de su familia

22 Ovidio recurre a una elipsis lógica: está claro que Medea ha dado su consentimiento y le ha explicado los hechizos, puesto que de otra forma no habría ni abandono ni lamento en la carta.

23 Como apunta Valverde Sanchez $(1996,267)$, con este gesto se formaliza el compromiso de matrimonio.

24 El primer encuentro de la pareja (A.R.3.975ff.) y el compromiso de matrimonio (A.R.4.95-99).

25 Otra opción de análisis es que se considere la historia que cuenta la epopeya como lo que "realmente" ocurrió, y que Medea en su escrito esté manipulando los hechos en su favor. No obstante, optamos por la interpretación 
es la nueva alianza con Jasón - que en el momento de escribir la carta ha perdido-, mientras que en la epopeya es la propia Medea la que, después de haber ayudado al héroe simplemente por amor -con la excusa de ayudar a su hermana-, le exige retroactivamente el compromiso de matrimonio. Así, la versión de la historia que se representa en la Heroida 12 influye en la verosimilitud tanto del retrato de inocencia de Medea como del duro discurso de acusación contra Jasón que plasma en la carta, pues lo ha perdido todo a cambio del lecho que ahora le arrebata.

Durante este pasaje de la Heroida encontramos otra variación con respecto a la versión de Apolonio. Ya hemos apuntado que, mientras que en la versión apolonia Medea responde a Jasón con un discurso de cómo debía usar sus hechizos para pasar a salvo las pruebas (A.R.3.1026-1062) en la carta se omite la respuesta de Medea y no encontramos nada sobre la explicación que le dio a Jasón. Así, mientras que en la epopeya Medea es constantemente representada como maga y seguidora de Hécate, en la Heroida toda esta representación tradicional sin duda está subyaciendo, pero se obvia en favor de dimensionarla especialmente como mujer ${ }^{26}$. Quizás en favor de este objetivo ovidiano haya una variación en el lugar del encuentro: en Apolonio se citan en el templo de Hécate, mientras que en la Heroida remarca que se citan en un bosque sagrado y no se refiere al templo de Hécate, sino a un templo de Diana ${ }^{27}$. Este cambio puede responder a una mitigación de la caracterización de maga de Medea, que incide en el retrato ya apuntado de la Medea del pasado como una muchacha ingenua ${ }^{28}$.

\section{El desarrollo de las pruebas y el robo del vellocino (Ov.Epist.12.93-108; A.R.3.1278-1407 y A.R.4.100-166)}

Justo después de terminar la escena del primer encuentro con Jasón, en la carta se comienza rápidamente el relato breve de las pruebas en cuatro dísticos (Ov.Epist.12.93$100)^{29}$. En los dos primeros encontramos una acción por verso, como subrayando la eficacia de la puella seducida. Tan eficaz es que la propia Medea se asusta del efecto de sus pócimas ${ }^{30}$.

La Medea de la carta relata a continuación cómo durmió al dragón para robar el vellocino $^{31}$ (Ov.Epist.12.101-108). En las Argonáuticas Jasón realiza las dos pruebas juntamente el mismo día por indicación de Eetes (A.R.3.1278-1407) y esa misma noche Medea, sospechando que su padre sabe que ha ayudado al extranjero, corre a encontrarse con Jasón y le ayuda a robar el vellocino para que la proteja de la ira de su padre (A.R.4.100-166). Pero en la carta se presenta el robo justo después de men-

presentada en el cuerpo de texto porque carece de sentido que Medea mienta a su destinatario sobre unos hechos que él conoce de primera mano.

26 Corrigan $(2013,65)$ afirma que Medea en la Heroida 12 no es representada como una maga, sino como una mujer dolida y rechazada, haciendo pocas menciones a su magia.

27 Hécate es una diosa afín a Ártemis (Grimal 1989, 225). El intercambio que realiza Ovidio no debe de justificarse por una cuestión de romanización, puesto que Hécate aparece por ejemplo en autores latinos como Cicerón (Cic. Nat.Deor.3.18.46).

28 Vid. supra. p. 16.

29 En cambio en las Argonáuticas se dedican 1030 versos (A.R.3.1278-1407) (Davis 2012, 38).

30 En la línea de lo apuntado al final del apartado anterior, se describe poco en la carta sobre la intervención de la magia en las pruebas, en lo que se explaya el narrador de la epopeya.

31 Hacia el final de la carta volverá a referirse al robo del vellocino (Ov.Epist.12.199-203). 
cionar las pruebas (Ov.Epist.12.101-108), sin hacer constar que son hazañas que responden a motivaciones y a momentos diferentes. Esta diferencia en la presentación de los hechos es importante para ver cómo narratológicamente la Heroida no tiene tantas exigencias como un género narrativo como la épica; además, es una muestra de cómo influye en lo narrado la perspectiva e intenciones del narrador, que en la carta es uno de los personajes.

Así, las tres hazañas quedan condensadas y yuxtapuestas en la carta, donde la escritora le dedica al vellocino el mismo espacio que a las dos pruebas de Jasón juntas. No obstante, la narración propiamente dicha del robo está contenida en dos dísticos (Ov.Epist.12.101-102, 107-108) separados entre sí por unos comentarios subjetivos de lamento de la voz de la narradora (Ov.Epist.12.103-106) que son provocados por el mismo recuerdo del relato. Cuando la escritora comienza a narrar el robo, describe brevemente al dragón (Ov.Epist.12.101-102), lo que le hace pensar en el vellocino y su voz subjetiva interrumpe la narración para expresar los sentimientos que el recuerdo le trae. Medea entonces dice: Dotis opes ubi erant? ubi erat tibi regia coniunx / Quique maris gemini distinet Isthmos aquas? (Ov.Epist.12.103-104) ${ }^{32}$. Nuestra heroína considera que el vellocino es la dote que le entregó a Jasón, y lo compara irónicamente con la dote de su nueva esposa Creúsa. Con esta comparación, Medea menosprecia las riquezas de la princesa de Corinto frente a lo que ella le ofreció: el vellocino y su propia salvación. Encontramos en las Argonáuticas también este motivo del vellocino como dote cuando Medea le pide a Jasón que la proteja de su padre llevándola con él, pues le ofrece el vellocino que le ayudaría a robar a cambio del compromiso de matrimonio

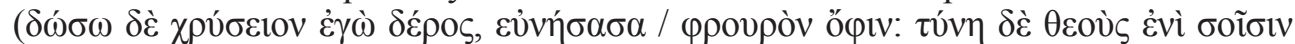

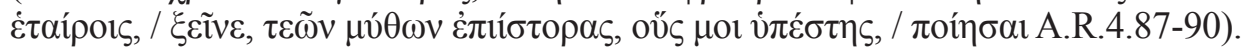

Por otro lado, al recordar a su destinatario que le ayudó en las hazañas, Medea se describe a través de los ojos de Jasón, y contrapone su retrato presente de mujer pobre y culpable (Illa ego, quae tibi sum nunc denique barbara facta, / Nunc tibi sum pauper, nunc tibi uisa nocens Ov.Epist.12.105-106) a lo que ella fue para él en el pasado, su poderosa salvadora y la persona que le entregó el vellocino. De esta manera, encontramos en la Heroida dos caracterizaciones de la Medea del pasado: sobre todo encontramos a la muchacha ingenua pero ahora se describe como una poderosa maga $^{33}$. Medea, que, como hemos visto ${ }^{34}$, insiste en describir su yo del pasado como una muchacha ingenua, deja entrever aquí, al describir la ayuda que prestó a Jasón, su caracterización de poderosa maga prototipizada por la tradición. Podríamos verlo como una caracterización contradictoria, pero no tiene por qué serlo ${ }^{35}$ : si Medea

32 Más adelante vuelve a referirse al vellocino como su dote (Ov.Epist.12.199-203).

33 Lindheim $(2003,125$ y 130) defiende que en la Heroida se da esta doble caracterización: una mujer poderosa capaz de realizar terribles actos por amor, y una chica inocente. Para esta estudiosa, el deseo lleva a Medea a crear dos retratos completamente diferentes de sí misma. Tradicionalmente se ha explicado esta dicotomía de Medea por la influencia de las dos fuentes: por un lado Eurípides, y por otro, Apolonio, aunque Lindheim opina, y por nuestra parte estamos de acuerdo, que hay importantes diferencias entre la Medea apolonia y la Medea puella de la carta, unas diferencias que esta estudiosa explica por la influencia de Hipsipila y Creúsa en su retrato. Para Corrigan (2013) esta doble caracterización no es tan evidente en la Heroida como en otras versiones del mito puesto que se sitúa en un momento muy concreto en el que no se produce ningún gran desarrollo en el personaje, que sólo reflejaría su imagen pasada de muchacha inocente. En nuestra opinión, ambos elementos del doble retrato, la maga y la simplex puella, en la Heroida describen a la Medea del pasado, no a la Medea que está escribiendo.

34 Vid. supra p. 16.

35 Verducci $(1985,71)$ considera que estos dos retratos son reconciliables. 
ayudó a Jasón utilizando los medios a su alcance es porque es crédula e inocente y por ello se deja manipular. Para la Medea de la carta, su carácter de hechicera es algo secundario, destacando su carácter de mujer enamorada.

\section{Medea y Jasón huyen de la Cólquide (Ov.Epist.109-128; A.R.4.167-1781)}

Después de narrar el robo del vellocino, lo siguiente que nos cuenta la escritora de la epístola es la huida de la Cólquide y la llegada a tierras tracias (Ov.Epist.12.109-128), acontecimientos que corresponden a lo narrado en el libro 4 de las Argonáuticas tras el robo del vellocino (A.R.4.167-1781). En esta parte de la carta destaca más en la voz de la heroína la función expresiva del lenguaje, pues plasma su culpabilidad por abandonar a su familia, pero el texto no pierde el hilo de lo que narra la epopeya puesto que desarrolla su sentimiento de culpa haciendo constantes referencias a los hechos clave de la historia.

La heroína mira con arrepentimiento lo que obtuvo a cambio de ayudar a Jasón, aludiendo a la huida y a la noche de bodas (Munus in exilio quod licet esse tuli, / Virginitas facta est peregrini praeda latronis $110-111)^{36}$, y pasa a enumerar tristemente a todos aquellos a quienes ha traicionado: su padre, su reino, su patria, su hermana y su madre. En este lamento Medea menciona a su hermano, una alusión de la que Ovidio se sirve para referirse al hecho más significativo que ocurre durante la huida de la Cólquide en las Argonáuticas: el asesinato de Apsirto. Al mencionarlo, la heroína de la carta da un giro a su discurso y comienza a apostrofarlo: At non te fugiens sine me, germane, reliqui; / Deficit hoc uno littera nostra loco; / Quod facere ausa mea est, non audet scribere dextra (Ov.Epist.12.113-115) ${ }^{37}$. Como vemos, mientras que en las Argonáuticas Apsirto es adulto y es asesinado por Jasón (A.R.4.411-521), en la Heroida Medea parece decir que es ella quien se lleva a su hermano y lo descuartiza para evitar que su padre los persiga. Esto apunta a que Ovidio sigue la versión del mito de Ferecides que recoge Apolodoro (Apollod.1.9.23) (Álvarez e Iglesias 2002:416), en la que además su hermano es un bebé ${ }^{38}$. En cualquier caso, lo importante aquí es remarcar que Ovidio, al crear una Medea que lleva a cabo este acto con

36 La noche de bodas en la epopeya (A.R.4.1128ff.) ocurre después de la muerte de Apsirto. Sin embargo, en la versión ovidiana, según hemos defendido en el cuerpo de texto, la unión matrimonial ocurriría en el momento en que Medea aceptó ayudar a Jasón, por lo que tiene sentido que mencione aquí la pérdida de su virginidad cuando habla del momento de la huida, antes de hablar de Apsirto.

37 En la carta, cuando Medea menciona a su hermano lo convierte en el interlocutor de sus palabras, olvidándose de Jasón por un momento. Con esta modificación del interlocutor cambia también la función del discurso, pues predomina completamente la función emotiva sobre la referencial del relato que le estaba recordando con reproche a su marido. De esta manera, son unos versos que se alejan del monólogo narrativo en el que se insertan y que podrían verse como un monólogo interno dentro del discurso que evoca, a modo de praeteritio, algo que afirma que no va a recordar. Teniendo en cuenta esto, podemos encontrar dos niveles en la carta: por un lado tenemos la narración y por otro, dentro del relato Medea realiza un comentario metareferencial sobre su propia escritura: no puede escribir sobre lo que hizo porque hay recuerdos que le hacen daño y que debe resumir o simplemente mencionar. Así, se produce una interrupción en la actitud de la voz narrativa de la carta: llegado el momento de la narración en que debe contar cómo huyeron, a nuestra heroína le invade la culpa y el arrepentimiento, reflexiona sobre ello y decide solamente mencionarlo.

38 Álvarez e Iglesias $(2002,416)$ recogen las tres versiones mitológicas de la muerte del hermano de Medea, entre las que se encuentra el descuartizamiento del bebé. Afirman que esta versión sería del gusto de Ovidio, quien también la usa en Tristia (Ov.Trist.3.9), donde amplía la información de Ov.Epist.6.129-130, una variante que también adaptaría Séneca. Quizás Ovidio sigua esta versión porque en la época fuera la versión más célebre, como puede indicar el hecho de que sea la versión que utiliza Cicerón (Cic.Manil.9.22). 
sus propias manos, le arrebata la inocencia que le habría concedido Apolonio ${ }^{39}$, y con ello pone en tela de juicio que en algún momento de su pasado Medea haya sido una simplex puella. En la versión de Ovidio, nuestra heroína es capaz de actos de gran violencia desde el principio, como el de matar a su propio hermano siendo un bebé: la gran ironía que presenta Ovidio consiste en que mató para salvar a Jasón, y matará para destruirlo.

El recuerdo de su hermano le provoca a Medea una gran rabia al pensar en todo lo que hizo por una persona que ingratamente la ha traicionado. Y así, en los versos 119-126 lamenta que no se cumpliera su deseo de morir junto a Jasón como castigo merecido por sus crímenes: tu fraudis poenas, credulitatis ego (Ov.Epist.12.120). Queda en este verso muy clara la esencia de la caracterización de ambos. Además, cabe señalar que nuestra heroína expresa este deseo refiriéndose elementos clave de la navegación de vuelta a Tesalia ${ }^{40}$, y de esta manera, aunque estemos en un monólogo subjetivo de carácter imprecatorio, la carta continúa siguiendo el hilo cronológico de las Argonáuticas (A.R.4.522-1781). Así, en esta parte hemos visto que se aluden en la carta a los siguientes sucesos de la epopeya: la huida, la muerte de Apsirto, la boda y la navegación de retorno.

\section{El final de la carta: recuerdos de las Argonáuticas (Ov.Epist.12.159-212)}

En los siguientes versos de la Heroida nuestra escritora relata los acontecimientos que ocurren después de lo narrado en las Argonáuticas. La epopeya termina tras narrar el viaje de vuelta a Tesalia, mientras que el relato de la Heroida se puede extender más allá en el tiempo del mito puesto que se escribe años después de que llegaran a Tesalia, cuando Medea y Jasón ya están establecidos en Corinto ${ }^{41}$. De una manera elíptica, mediante la mención del asesinato de Pelias (Ov.Epist.12.129-32) la carta establece una transición entre la historia del vellocino -el pasado de Medea, las Argonáuticas-y lo que ocurre en Corinto -el momento presente de la escritura, poco después de que Jasón la repudie y se case con Creúsa y justo antes de que comience a planear su venganza contra é ${ }^{42}$. La carta finaliza con un monólogo subjetivo en el que la heroína sigue recordando los acontecimientos de las Argonáuticas. En este monólogo se pueden ver las distintas fases por las que pasan los sentimientos de la heroína ${ }^{43}$ al mismo tiempo que intercala en su discurso los eventos más importantes de su pasado apolonio como argumentos contra Jasón: evoca la traición a su padre (Ov.Epist.12.159-162), la ayuda que prestó a Jasón en las pruebas y en el robo del vellocino (Ov.Epist.12.163-171,195-196, 199-203), y el juramento de Jasón (Ov. Epist.12.194).

39 Una inocencia que a su vez es cuestionable, puesto que en las Argonáuticas, si bien Medea no mata a su hermano con sus propias manos, es ella quien maquina el plan que lleva a cabo Jasón. Aunque es muy probable que la intención de Apolonio fuera suavizar su culpabilidad.

40 Como las Simplégades (Ov.Epist.12.121-122) y Escila y Caribdis (Ov.Epist.12.123-126).

41 Vid. supra p. 13.

42 Pero hay algo más que ha ocurrido entre el asesinato de Pelias y el momento en que está escribiendo la carta: Jasón repudia a Medea y celebra su boda con Creúsa (Ov.Epist.12.133-158). Vid. supra nota 16.

43 Vuelve a echarle en cara a Jasón todo lo que ha hecho y ha abandonado porél(Ov.Epist.12.159-162,173-4,199-206), expresa cómo se siente en su situación de abandono (Ov.Epist.12.163-172), le suplica que vuelva con ella (Ov. Epist.12.183-198) y amenaza con destruir a sus enemigos (Ov.Epist.12.175-182). 
Medea comienza este último monólogo comparando su situación actual de pasividad con su pasado de poderosa maga y recuerda las pruebas en las que asistió a Jasón (Ov.Epist. 12.163-171) ${ }^{44}$. Recuerda especialmente que durmió al dragón con su magia (Ov.Epist.12.171) y así utiliza la versión de Apolonio, y no la de Eurípides en la que lo mata. La heroína caracteriza su magia no de mortífera sino de protectora, y de esta manera renegocia su identidad en el final de su discurso yendo en contra de su reputación literaria de poderosa destructora. Algo que le conviene hacer sobre todo después de haber mencionado de nuevo a su difunto hermano (Ov.Epist.12.160). ¿Por qué Ovidio utilizaría la versión en la que mata a su propio hermano y se quedaría con la que adormila al dragón? Quizás porque con ella representa a una Medea que puede destruir sin la magia y puede empuñar la espada si el momento lo requie$\mathrm{re}^{45}$.

En cuanto el hilo de pensamiento de Medea la lleva a mencionar a su rival amorosa, Creúsa, comienza a invadirle la rabia (Ov.Epist.12.173-182). Medea considera a la princesa como no merecedora del amor de Jasón, pues no es ella quien lo ha salvado, y la presenta despectivamente como no legítima, estúpida y arrogante ${ }^{46}$ (paelex 173; stulta 175; sublimis 179). Nuestra escritora teme ser objeto de burla de Creúsa y amenaza con vengarse de sus enemigos (Ov.Epist.12.178-182), pues no tiene intención de dejar que se rían de ella ${ }^{47}$. Justo después de la amenaza, tenemos un monólogo suplicante (Ov.Epist.12.183-198). Apreciamos así la espontaneidad de la escritora y la fluidez de sus pensamientos. Medea se humilla ante Jasón para que vuelva con ella y utiliza los mismos argumentos que ha estado utilizando a lo largo de su discurso - el recuerdo del juramento y todo lo que ha dado por él-pero además añade el argumento de sus hijos comunes, que apunta irónicamente al futuro trágico. Luego su voz se vuelve arrogante e insiste en que merece su lecho pues gracias a ella está vivo: ella ha pagado su dote, no con el dinero que tanto ansía de su nueva esposa, sino con la fama que le trajo el vellocino y con la propia salvación de su vida (Ov.Epist.12.199-204). Hay una deuda entre los dos, antes estaba saldada con el matrimonio, ahora está pendiente de nuevo. Parece que quiera saldar esa deuda matando a la princesa y a su padre Creonte (Ov.Epist.12.205-208), pero no a Jasón, quizás porque en la carta aún quiere recuperar su lecho. Como vemos, todavía no termina de convertirse en la Medea de Eurípides, cuyo plan va encaminado a la pura venganza y no a recuperar a su marido. Los siguientes y últimos versos pronostican

44 Una ayuda que más adelante vuelve a rememorar esta vez como argumento para que regrese con ella (Ov. Epist.12.195-197)

45 Como hemos dicho, parece que Ovidio no pretende caracterizarla de inocente dado que la presenta como asesina, pero esto no significa que realice un retrato de una criminal, pues todo el discurso -su manera de narrar, sus interpolaciones a la narración, este monólogo subjetivo final- constituye una prueba en palabras de la lucha interna de Medea, que se encuentra sumida en su propia culpabilidad, su deseo de recuperar a Jasón, su necesidad de reprocharle todo lo ocurrido al traidor, y su incipiente rabia. Tanto Eurípides como Apolonio han utilizado la lucha interna de Medea en forma de monólogos internos para hacer que el lector sienta empatía por el personaje (Papadopoulou 1997) y esto en manos de Ovidio ha culminado en la Heroida, una construcción de la mente de Medea, de su historia y de sus sentimientos en un momento del mito jamás contado.

46 Una forma habitual de presentar a la rival amorosa en las Heroidas (Rosati 1993,74-84).

47 Este motivo resulta interesante pues es compartido también por las Medeas de la epopeya y de la tragedia euripidea (E.Med.797; A.R.4.389-390). Los enemigos de Medea cambian según la obra, y por tanto, según el momento del mito. En la Heroida, teme ser objeto de burla de Creúsa, la rival amorosa; en las Argonáuticas no va a permitir que se burlen de ella el propio Jasón y los griegos; y en Medea sus enemigos son Creúsa, Jasón y Creonte (E.Med.374-5), pero sobre todo los dos últimos, a los que no está dispuesta a perdonar porque se han reído de ella faltando a su honor. 
la tragedia de Eurípides: Quo feret ira, sequar. Facti fortasse pigebit; / Et piget infido consuluisse uiro. / Viderit ista deus, qui nunc mea pectora uersat. / Nescio quid certe mens mea maius agit (Ov.Epist.12.209-212). La Medea de la carta está a punto de convertirse en la Medea de la tragedia, pero aún no es una heroína trágica.

\section{Consideraciones finales}

La Medea que escribe la Heroida es la mujer abandonada que quiere recuperar su matrimonio, aunque esta caracterización resulta muy simplista si olvidamos un factor clave: su sentimiento de culpa por haber traicionado a su familia y a su reino por un hombre que ha terminado abandonándola. Ovidio nos presenta a una Medea que en la carta explora su culpabilidad, y que para apaciguar su ánimo culpabiliza a Jasón recordándole la historia apolonia. Este es un aspecto esencial de la epístola: el reproche a Jasón, que gira en torno a tres argumentos: 1) el héroe ha roto el juramento que le hizo a la joven Medea de entregarle, sólo a ella, su lecho; 2) ella ha traicionado y abandonado su patria por él y, por último, 3) Jasón está vivo y en poder del vellocino sólo gracias a ella. Hay un discurso de Medea en las Argonáuticas que anticipa estos tres aspectos esenciales del discurso de la Heroida. En plena huida de la Cólquide, cuando los colcos le ofrecen a Jasón un pacto para que se quede con el vellocino a cambio de que deje a Medea en custodia para que un rey decida su destino ${ }^{48}$, nuestra heroína le recuerda amenazante a su amado los juramentos que él le había hecho cuando ella decidió ayudarlo (A.R.4.355-390):

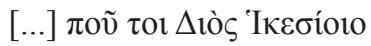

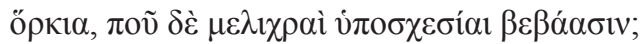

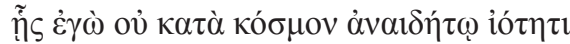

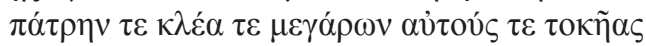

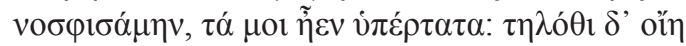

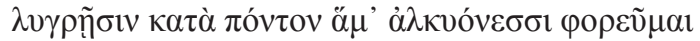

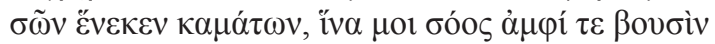

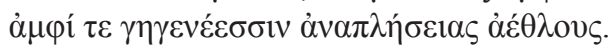

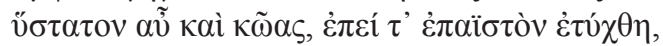
$\varepsilon \tilde{i} \lambda \varepsilon \varsigma \dot{\varepsilon} \mu$ ñ $\mu \alpha \tau i ́ n$ [...] (A.R.4.358-367)

En este discurso Medea le exige a Jasón que la proteja utilizando los tres argumentos mencionados ${ }^{49}$. Con estos mismos tres argumentos, como hemos visto, en la Heroida también le pide algo: que le devuelva su lecho ${ }^{50}$. Por tanto, la heroína de la epístola tiene dos objetivos encontrados: mitigar su culpa y recuperar su lecho. Pero la necesidad de apaciguar su ánimo y el dolor por la traición de su esposo resultan más poderosos que su necesidad de recuperarlo y por ello no utiliza un lenguaje de seducción sino que lo ataca duramente, esperando a su vez que, haciéndolo sentir

48 Como ocurrirá en efecto luego con Alcínoo (A.R.4.1004ff.).

49 Le recuerda el juramento (A.R.4.358-9), que ha traicionado a su familia (A.R.4.361-2), y que, tras salvarlo, le entregó el vellocino (A.R.4.364-67).

50 Entendamos que Medea quiere recuperar el honor, no al amante; y el honor de una mujer casada, que además es madre, se construye en la permanencia del matrimonio simbolizado por el lecho. 
culpable, vuelva con ella. Para defender la legitimidad de su petición, Medea utiliza el tercer argumento: ella, al salvarle la vida y entregarle el vellocino, ha comprado su lecho. Se siente su compañera, su socia, poseedora por derecho propio de todo lo que tiene Jasón, de su fama y de su gloria ${ }^{51}$.

Pero hay algo más sobre el pasaje de las Argonáuticas citado. En él se materializan los reproches que Medea le había dicho antes a Jasón, durante su primer encuentro a solas, que esperaba no tener que echarle en cara (A.R.3.1115-1116). Estos reproches son un lugar común en las tres obras: la Medea de Eurípides, las Argonáuticas y la Heroida 12. En la Medea, cuando ya ha sido abandonada, nuestra heroína le recrimina todo lo que ha hecho por él y le recuerda los acontecimientos de la Cólquide (E.Med.465-519). Apolonio, conociendo el mito de principio a fin, crea un vínculo irónico entre su texto y el de Eurípides, imaginando a una Medea que comienza a recriminarle desde el principio, como si supiera lo que su futuro le depara. Y la misma prolepsis explota Ovidio en la carta, quien también conoce el final de su historia, concediéndole a nuestra heroína el espacio y el medio que necesitaba para plasmar esos reproches que han pincelado sus antecesoras literarias pero que no han llegado a exponer en toda su magnitud. Por tanto, la Heroida 12 es ese reproche y esa extensa rememoración (Davis 2012, 38) que no pudo darse en su plenitud en la tragedia y que ya previó nuestra heroína en las Argonáuticas. Así, esta narración en boca de Medea de la historia del robo del vellocino de oro compartida por la tragedia y la Heroida se presenta como una respuesta a la necesidad de la heroína transversal en las tres obras de echarle en cara a Jasón todo lo que hizo por él. En la Heroida Medea no se limita a repasar su pasado apolonio, lo transforma en un poderoso discurso de acusación (Davis 2012, 40).

\section{Conclusiones: la jerarquización de las Argonáuticas como intertexto}

En definitiva, la carta de Medea contiene una importante parte narrativa que relata el pasado de la heroína desde que conoció a Jasón hasta que este se casa con Creúsa; el resto de la carta es un monólogo subjetivo que oscila entre el lamento y el reproche. El relato de la boda de Jasón y Creúsa en la carta no parece estar basado en ningún hipotexto claro, por lo que podemos suponer que es innovación de Ovidio. Pero para narrar los acontecimientos de la Cólquide hemos demostrado a lo largo de este artículo que la Heroida 12 utiliza como modelo los cantos 3 y 4 de las Argonáuticas, cuyo relato sigue cronológicamente en una parte narrativa que ocupa la mitad de la carta $^{52}$. Pero no debemos quedarnos sólo en esta mera descripción de los hechos, conviene apuntar en nuestras conclusiones cómo se jerarquiza las Argonáuticas con respecto a otros posibles intertextos. Ovidio toma el contenido de los cantos 3 y 4 y los filtra por la perspectiva de la nueva narradora en primera persona, y así establece un proceso intertextual del que se sirve para que su heroína del presente de la carta renegocie la identidad que le viene dada por su pasado literario. La Heroida 12, pues, sigue a Apolonio en el contenido narrativo, pero también se basa en la epopeya para

\footnotetext{
51 Otras heroínas de la colección reclaman el lecho de su amado desde su posición de esposa legítima, mientras que Medea lo hace como la persona que le salva la vida, y eso hace que a su condición de heroína femenina se unan rasgos heroicos masculinos por ser la salvadora de Jasón.

52 Sin olvidarnos de que también se evocan sucesos de dicha historia en las partes subjetivas del discurso.
} 
crear la voz de su heroína. Del análisis de las voces intertextuales podemos comprobar que la Medea de Ovidio se diferencia de la de Apolonio especialmente debido a la divergencia del momento del mito en que se inserta. La Medea de Ovidio ha sido una muchacha enamorada cuya historia de amor naufragó en el momento en el que su amado la repudió. Desde ese momento se convierte en la mujer que escribe la carta, una mujer llena de rencor y culpa que le reprocha a su interlocutor que la haya abandonado. Ese rencor poco a poco va convirtiéndose en ira, una ira que finalmente la poseerá para entrar en la escena trágica tras dejar de escribir ${ }^{53}$. A grandes rasgos la Medea de la carta es el futuro de la Medea de Apolonio y el pasado de la euripidea.

Esta sería, por tanto, nuestra conclusión: Ovidio sigue los cantos 3 y 4 de $A r$ gonáuticas en el nivel de la materia narrativa. Y, aunque en la voz de la heroína ya vemos algunas muestras prolépticas, a partir de referencias intertextuales, de la historia que se desarrolla en las tragedias de la venganza, estas tragedias no influyen demasiado en la materia narrativa de la Heroida dado que narran sucesos que aún no han ocurrido cuando Medea escribe la carta. Donde entran a jugar un papel importante los intertextos trágicos es a nivel puramente estructural y genérico, pues, como hemos apreciado al analizar la carta al completo con sus posibles intertextos ${ }^{54}$, en la Heroida 12 se traslada la forma dramática mediante la transcodificación de elementos estructurales de dicho género ${ }^{55}$, de manera que Ovidio recrea en la carta una verdadera tragedia de Medea, que gira en torno a su abandono.

En definitiva, la Heroida 12 es el producto de una compleja intersección de niveles intertextuales, entre los cuales se encuentra su relación con las Argonáuticas, obra con la que mantiene un diálogo abierto, transformando las múltiples alusiones al texto de Apolonio en un nuevo texto dentro de género literario distinto que a su vez se ve influido por otros hipotextos, creando una interesante red de ironías e referencias.

\section{Referencias bibliográficas}

Álvarez Morán, M. C. e Iglesias Montiel, R. M. (2002), «Cruce de géneros en las Metamorfosis. Medea entre la épica y la tragedia», en López López, A. y Pociña Pérez, A. (eds.), Medeas, versiones de un mito desde Grecia hasta hoy, I, Granada, Universidad de Granada, 411-445.

Barchiesi, A. (2001a), «Narrativity and Convention in the Heroides», en Fox, M. y Marchesi, S. (eds.), Speaking Volumes, Londres, Duckworth, 29-47.

- (2001b), «Future reflexive: Two modes of Allusion and Ovid's Heroides» en Fox, M. y Marchesi, S. (eds.), Speaking Volumes, Londres, Duckworth, 105-127.

Blázquez Noya, A. (2017), «Medea en Heroidas 12: una heroína elegíaca», en De la Villa Polo, J. et al. (eds.), Conuentus Classicorum. Temas y formas del Mundo Clásico, I, Madrid, Sociedad Española de Estudios Clásicos, 769-776.

53 Debido al pobre estado de conservación de las otras tragedias de la venganza, nos referiremos a la de Eurípides porque, al conservarse completa, es con la única con la que se pueden llegar a unas conclusiones fundadas.

54 Esta idea de la estructura dramática de la Heroida 12, que hemos desarrollado en estudios aún no publicados, queda apuntada aquí de manera concisa y sin desarrollar como ejemplo de que no se debe considerar las Argonáuticas como el único intertexto de la Heroida y de que los hipotextos juegan papeles diferentes en el proceso intertextual según el nivel en el que se encuentren.

55 Como por ejemplo el discurso del mensajero. 
Boyle, A. J. (2012), «Introduction: Medea in Greece and Rome», Ramus 41, 1-32.

Casali, S. (1995), «Tragic irony in Ovid, Heroides 9 and 11», CQ 45, 505-511.

Corrigan, K. (2013), Virgo to Virago: Medea in the Silver Age, Cambridge, Cambridge Scholars Publishing.

Fulkerson, L. (2005), The Ovidian Heroine as Author. Reading, Writing and Community in the Heroides, Cambridge, Cambridge University Press.

Giandrande, G. (2002), «Medea y la concepción del amor en Apolonio Rodio», en López López, A. y Pociña Pérez, A. (eds.), Medeas, versiones de un mito desde Grecia hasta hoy, I, Granada, Universidad de Granada, 329-346.

Grimal, P. (1989 [1971]), Diccionario de la mitología griega y romana, Barcelona, Paidós.

Hinds, S. (1993), «Medea in Ovid: scenes from the life of an intertextual Heroine», MD 30, $9-47$.

Jacobson, H. (1974), Ovid's Heroides, Princeton, Princeton University Press.

Jolivet, J. C. (2001), Allusion et fiction épistolaire dans les Hérö̈des: Recherches sur l'intertextualité ovidienne, Paris, Collection de l'École Française de Rome, 289.

Kennedy, D. (2002), «Epistolarity: The Heroides», en Hardie, Ph. (ed.), The Cambridge Companion to Ovid, Cambridge, Cambridge University Press, 217-232.

Knox, P. E. (1986), «Ovid's Medea and the Authenticity of Heroides12», HSPh 90, 207-23.

Lindheim, S. H. (2003), Mail and Female. Epistolary Narrative and Desire in Ovid's Heroides, Wisconsin, University of Wisconsin Press.

Mooney, G. W. (1912), Argonautica of Apollonius Rhodius, edited with introd. and commentary by George W. Mooney, Londres, Longmans, Green \& Co.

Moya del Baño, F. (1986), Ovidio. Heroidas, Texto revisado y traducido, Madrid, CSIC.

Papadopoulou, T. (1997), «The Presentation of the Inner Self: Euripides' Medea 1021-55 and Apollonius Rhodius' Argonautica 3. 772-801», Mnemosyne 50 (6), 641-664.

Rosati, G. (1993), «L'elegia al femminile: le Heroides di Ovidio (e altre heroides)», MD 29, $71-74$.

Valverde Sánchez, M. (1996), Apolonio de Rodas. Argonáuticas, introducción, traducción y notas de Mariano Valverde Sánchez, Madrid, Editorial Gredos.

Verducci, F. (1985), Ovid's toyshop of the heart: Epistulae heroidum, Princeton, Princeton University Press. 